\title{
Editorial: Role of Endophytes in Plant Health and Defense Against Pathogens
}

\author{
Massimiliano Morelli ${ }^{14}$, Ofir Bahar ${ }^{2 \dagger}$, Kalliope K. Papadopoulou ${ }^{3 \dagger}$, Donald L. Hopkins ${ }^{4 \dagger}$ \\ and Aleksa Obradović ${ }^{5 t}$ \\ ${ }^{1}$ Consiglio Nazionale delle Ricerche, Istituto per la Protezione Sostenibile delle Piante, Sede Secondaria di Bari, Bari, Italy, \\ 2 Department of Plant Pathology and Weed Research, Agricultural Research Organization (ARO), Rishon LeZion, Israel, \\ ${ }^{3}$ Department of Biochemistry and Biotechnology, University of Thessaly, Larissa, Greece, ${ }^{4}$ University of Florida, Gainesville, \\ FL, United States, ${ }^{5}$ Faculty of Agriculture, University of Belgrade, Belgrade, Serbia
}

\section{OPEN ACCESS}

Edited by:

Essaid Ait Barka,

Université de Reims ChampagneArdenne, France

Reviewed by:

Sameh Selim,

UniLaSalle, France

*Correspondence:

Massimiliano Morell

massimiliano.morelli@ipsp.cnr.it

${ }^{\text {t}}$ These authors have contributed equally to this work

Specialty section: This article was submitted to Plant Pathogen Interactions,

a section of the journal

Frontiers in Plant Science

Received: 29 June 2020 Accepted: 11 August 2020

Published: 26 August 2020

Citation:

Morelli M, Bahar O, Papadopoulou KK, Hopkins DL and Obradović A (2020) Editorial: Role of Endophytes in Plant Health and Defense Against Pathogens.

Front. Plant Sci. 11:1312. doi: 10.3389/fp/s.2020.01312
Keywords: endophytes, metagenomics, plant defense response, bioactive compounds, bioinoculants, plant growth-promoting bacteria

\section{Editorial on the Research Topic}

Role of Endophytes in Plant Health and Defense Against Pathogens

\section{INTRODUCTION}

With the increasing social concern in avoiding, or at least reducing, the application of pesticides and chemical fertilizers, in favor of sustainable eco-friendly alternatives, the search for beneficial microorganisms and microbial-derived compounds has become one of the most popular Research Topics in the field of plant-microbe interactions (Cardoso Filho, 2019; Omomowo and Babalola, 2019).

Bacterial and fungal endophytes ubiquitously inhabit plant tissues without causing any adverse effect. On the contrary, their presence is often of benefit for the host, as they improve tolerance to abiotic adversities, enhance growth, and, relevantly, can modulate plant immune response and suppress pathogen colonization (Dini-Andreote, 2020). Since endophytic microorganisms typically cover the same ecological niches occupied by fungal and bacterial phytopathogens, they have been widely proposed as biocontrol agents that could be used as an alternative to pesticides (Compant et al., 2013).

Thanks to the multifaceted role they play, endophytic microbial resources are now considered crucial in the perspective of their potential use to achieve sustainable improvements in the agro-food system. As a consequence, there is now a scientific ferment trying to analyze every aspect of their interaction with plants and associated pathogens.

With 16 Original Research Articles and one Review, this Research Topic provides an overview of the current state of the art on the large research effort currently dedicated to understanding the role of endophytes in plant health and defense against pathogens.

\section{A CROSSTALK WITH PLANT DEFENSE PATHWAYS}

Among the most challenging aspects resulting from the investigation on the application of endophytes, and in particular of plant growth-promoting bacteria (PGPB), there is the ability of 
several strains to trigger plant defense mechanisms (Ma, 2017). Commonly, PGPB-induced systemic resistance (ISR) is found to be associated with the up-regulation of genes involved in the pathways of jasmonic acid and ethylene (Pangesti et al., 2016). Biochemical responses such as increased synthesis of reactive oxygen species (ROS) and phenolic metabolites (Benhamou, 1996; Samain et al., 2017) are often associated with ISR, as well as anatomical modifications like the deposition of callose and lignin in the endophyte-colonized tissues (Benhamou, 1996; Constantin et al., 2019).

The blurred distinction between ISR and the pathogeninduced systemic acquired resistance (SAR) (Van Loon et al., 1998) was manifested in the study of Samain et al., in which certain Paenibacillus strains (i.e. PB2), when used to control Mycosphaerella graminicola, induced up-regulation of genes, such as pathogenesis-related proteins (PR1) and chitinases, usually considered as markers of SAR. This peculiar induced resistance is of interest, as it may be a more usual phenomenon, previously observed in other PGPB genera, like Bacillus and Pseudomonas (Park and Kloepper, 2000; Trotel-Aziz et al., 2008; Samain et al., 2017) and confers wheat a durable resistance. Its mode of action, which appears to be significantly influenced by the pathogen strain, the plant growth phase, and its genotype, needs to be addressed in further detail.

The duration of the resistance effect to pathogen-induced biotic stresses that endophytes may activate is, indeed, a key point in management strategies. In highlighting the ability of Rhizobium etli, a common bean symbiont to activate robust defense responses against the pathogen Pseudomonas syringae pv. phaseolicola, Diaz-Valle et al. noted that $R$. etli-primed plants seem to develop a transgenerational defense memory. The persistence of this capability in F1 generation appears to be related to transcription factors, independent from ethylene signaling pathway, and again, involved in the activation of PR gene expression, as already proposed by (Huang et al., 2016).

Although in recent years associative symbioses have been widely studied in several beneficial bacteria (Ahemad and Kibret, 2014; Coutinho et al., 2015), relatively few studies analyzed their effects on the transcriptional response of plants. Relying on an established model of symbiosis, that constituted by rice and Burkholderia sensu lato (s.1.) (Cottyn et al., 2001; Mannaa et al., 2019), King et al. have described the differences in transcriptional regulations induced by two closely related PGPB with different phylogenetic and ecological backgrounds. Each strain induced a unique expression pattern in the jasmonic acid signaling pathway, and, interestingly, differences have been related to distinct colonization strategies.

Biochemical changes triggered in plants challenged with PGPB are often combined with anatomical alterations. Rodriguez et al. have shown that Gluconacetobacter diazotrophicus is capable of inducing a series of structural changes in inoculated Arabidopsis thaliana seedlings through the deposition of callose. As a result of this sclerosis in root, stem, and leaf tissues, the plant reinforces cell wall and withstands colonization by Ralstonia solanacearum responsible for wilt disease.

\section{COOPERATIVE ENDOPHYTE-MEDIATED RESISTANCE}

The study by de Lamo and Takken focuses on an interesting example of endophyte-mediated resistance (EMR), a mechanism that seems distinct from ISR and SAR, as jasmonate, ethylene, and salicylic acid are not involved (Pieterse et al., 2014; Constantin et al., 2019). In this case, the target plant (tomato) established a tri-partite interaction with two different strains of the same root-invading fungus (Fusarium oxysporum). While pathogenic strains employ host-specific effectors to interfere with host immune signaling (van Dam et al., 2018), co-inoculation of pathogenic Fusarium strains with endophytic Fusarium strains induces resistance responses and reduces negative disease effects. This kind of tri-partite interactions that leads to EMR was also investigated by Del Barrio-Duque et al. In the attempt to identify bacterial strains that stimulate the growth of the beneficial fungus Serendipita indica (Varma et al., 1999; Gill et al., 2016), the authors found that strains belonging to Mycolicibacterium genus might boost the beneficial effects triggered by $S$. indica on tomato plants, while decreasing severity of the symptoms caused by F. oxysporum and Rhizoctonia solani. This example of cooperation in triggering the host response is intriguing, as it could be explained by the presence in the helper's genome of several genes involved in vitamin and secondary metabolite production that might supplement $S$. indica bioenergetic capacity. Thus, cooperation among cross-talking microbial players may be needed to restrain pathogen colonization (Zuccaro et al., 2011; Salvioli et al., 2016).

\section{ENDOPHYTES PRODUCE A VARIETY OF EXPLOITABLE BIOACTIVE METABOLITES}

An interesting facet of the interaction between endophytes and their hosts is the capacity of many microorganisms to improve the plant's resistance by providing several bioactive metabolites (Gunatilaka, 2006). In some cases, the release of volatile compounds emitted by plant-associated bacteria has risen to the fore as a promising sustainable strategy to prevent the proliferation of above-ground fungal pathogens (Köberl et al., 2013; Bailly and Weisskopf, 2017; Garbeva and Weisskopf, 2020). Bruisson et al. have identified in grapevine leaf microbiome two Bacillus subtilis and B. cereus strains able to inhibit the growth of Phytophthora infestans, putatively through the emission of volatile compounds identified among pyrazines, chalconoids and tryptophan-derivatives.

The study by Teimoori-Boghsani et al. sheds light on another aspect of great interest, such as the potential of endophytes isolated from Salvia abrotanoides (Kar.) to induce synthesis of the bioactive diterpenoid cryptotanshinone by the plant and while doing that to produce the same molecule independent of the host. Their findings confirm the ability of endophytes to hijack the host's metabolic setups while providing an interesting basis for agricultural and pharmaceutical exploitation of 
medicinal plants for the production of higher amounts of bioactive constituents.

\section{COMBINING CLASSICAL AND MODERN APPROACHES TO STUDY THE PLANT- ASSOCIATED MICROBIOTA}

In recent years, it has become clear that the complex structure of plant-associated microbial communities is a major driver of plant health (Lebeis et al., 2012; Bulgarelli et al., 2013), and a deeper understanding of the endophytic microbiome has the potential to become a pivotal tool for reducing the incidence of plant disease (Bloemberg and Lugtenberg, 2001).

In recent decades, plant microbial ecology has experienced a relentless proliferation of available techniques, and this multiplicity of approaches is also reflected in the studies gathered in our Research Topic. In exploring a wide array of different plant environments, the proposed studies ranged from culturedependent screenings, where bacterial and fungal communities were profiled using PCR amplification of $16 \mathrm{~S}$ ribosomal RNA gene or Internal transcribed spacer (ITS), as in Abdelshafy Mohamad et al., Teimoori-Boghsani et al., Bruisson et al., toward high-throughput technologies, as in the metagenomics strategy proposed by Liu et al., Araujo et al., Elsayed et al., and AnguitaMaeso et al.

This recourse to NGS technologies has provided a fundamental contribution, as they allow to reveal the presence of even rare microbial species and the interactions between these complex communities and their hosts, reaching a depth of resolution previously unimaginable (Bentley et al., 2008; Lebeis et al., 2012). Nevertheless, the importance of combining both culture-dependent and -independent methods to characterize the plants' microbiota was nicely illustrated by Anguita-Maeso et al., and provided support to the notion that no one method can capture the plant microbiome in its entirety. This notion appears to be especially relevant to the characterization of endophytic communities inhabiting nutritionally poor environments, such as the xylem vessels in perennial crops (Aranda et al., 2011; Mendes et al., 2011; Dissanayake et al., 2018).

\section{THE RISING ROLE OF STREPTOMYCES AND SOIL-BORN ENDOPHYTES}

As reviewed by Romano et al., the availability of the identification methods, not merely based on morphological characteristics, is of paramount importance to complement traditional methodologies in screening persistence of bioinoculants in the rhizosphere and their pattern of synergy with native microorganisms sharing the same niche. The interactions between rhizosphere and endosphere microbiomes and its dynamics have proved to play a critical role in shaping the agronomic traits of crop plants (Schlaeppi and Bulgarelli, 2015) and their study may help to identify effective biocontrol strains that can promote crop yield and reduce the consequences of serious infestations.

Among rhizosphere colonizers Streptomyces spp. are building a reputation as biocontrol agents against mycotoxigenic fungi, including numerous Fusarium spp. threatening cereal crops (Palazzini et al., 2007; Jung et al., 2013; Colombo et al., 2019). Colombo et al. identified an effective Streptomyces strain that was able to dramatically reduce Fusarium head blight symptoms in wheat and to prevent pathogen spread. Liu et al. provided evidence that Streptomyces strains isolated from Glycine max rhizosphere show excellent growth-promoting activity in soybean, in addition to delivering an important antagonistic activity against Sclerotinia stem rot disease. This two-side beneficial activity also resulted in the efforts of Araujo et al. who demonstrated the successful application of Streptomyces strains to accelerate the maturation of wheat heads and positively interfere with root microbiome challenged with severe $R$. solani infestation.

\section{CONCLUDING REMARKS AND FUTURE CHALLENGES}

Summarizing its overall heterogeneous composition, this Research Topic well represents the variety of experimental approaches and possible directions in studying this broad and very attractive area of science. The collection of results, presented in the papers, opened a unique knowledge window to the determinants and mechanisms that regulate the dual plant-endophyte interplay, and at the same time, to increased levels of complexity of the tri-partite interaction with phytopathogenic agents that cause severe diseases. The proposed approaches provide insights crucial for the development of new agro-biotechnological strategies for plant protection that will improve food security and environmental sustainability.

We also see our effort as an opportunity to feed the debate on several open questions that clearly emerged from the proposed research. For instance, we may point out the need to complement traditional microbiological approaches with next-generation -omics technologies, to capture as much diversity as possible (Singh, 2019). There is also the necessity to strengthen the newly discovered evidence by providing bio-analytical methods that allow tracking the persistence of bioinoculants and to understand their relationships with the autochthonous microbial communities, in the environments where they are released. Last but not the least, the alert on possible biosafety issues. So far, we just gained a partial knowledge on metabolic profiles of the majority of the components of plant-associated above-ground communities. However, we should be aware that the absence of phylogenetic relationships with human pathogens does not imply that endophytes do not present any risk for our health. Biosafety characteristics should be well addressed before proceeding with the environmental application (Keswani et al., 2019).

Based on these grounds, we believe that the multidisciplinary approach, proposed in our compendium, may result in the best strategy stimulating fast scientific progress on this challenging issue. 


\section{AUTHOR CONTRIBUTIONS}

$\mathrm{MM}$ wrote the draft and submitted the final version. $\mathrm{OB}, \mathrm{KP}, \mathrm{DH}$, and $\mathrm{AO}$ edited the manuscript and provided critical review. All authors contributed to the article and approved the submitted version.

\section{FUNDING}

The participation of KP was partially funded by the General Secretariat for Research and Technology (GSRT) under the PRIMA Programme (INTOMED Project). AO was supported

\section{REFERENCES}

Ahemad, M., and Kibret, M. (2014). Mechanisms and applications of plant growth promoting rhizobacteria: current perspective. J. King Saud Univ.-Sci. 26 (1), 120. doi: 10.1016/j.jksus.2013.05.001

Aranda, S., Montes-Borrego, M., Jiménez-Díaz, R. M., and Landa, B. B. (2011). Microbial communities associated with the root system of wild olives (Olea europaea L. subsp. europaea var. sylvestris) are good reservoirs of bacteria with antagonistic potential against Verticillium dahliae. Plant Soil 343 (1-2), 329-345. doi: 10.1007/s11104-011-0721-2

Bailly, A., and Weisskopf, L. (2017). Mining the volatilomes of plant-associated microbiota for new biocontrol solutions. Front. Microbiol. 8, 1638. doi: 10.3389/ fmicb.2017.01638

Benhamou, N. (1996). Elicitor-induced plant defence pathways. Trends Plant Sci. 1 (7), 233-240. doi: 10.1016/S1360-1385(96)86901-0

Bentley, D. R., Balasubramanian, S., Swerdlow, H. P., Smith, G. P., Milton, J., Brown, C. G., et al. (2008). Accurate whole human genome sequencing using reversible terminator chemistry. Nature 156 (7218), 53-59.

Bloemberg, G. V., and Lugtenberg, B. J. J. (2001). Molecular basis of plant growth promotion and biocontrol by rhizobacteria. Curr. Opin. Plant Biol. 4 (4), 343350. doi: 10.1016/S1369-5266(00)00183-7

Bulgarelli, D., Schlaeppi, K., Spaepen, S., Van Themaat, E. V. L., and SchulzeLefert, P. (2013). Structure and functions of the bacterial microbiota of plants. Annu. Rev. Plant Biol. 64, 807-838. doi: 10.1146/annurev-arplant-050312-120106

Cardoso Filho, J. A. (2019). "Production and Application of Novel Bio-active Compounds by Endophytic Microbes," in Natural Bio-active Compounds (Singapore: Springer), 1-40.

Colombo, E. M., Kunova, A., Cortesi, P., Saracchi, M., and Pasquali, M. (2019). Critical Assessment of Streptomyces spp. Able to Control Toxigenic Fusaria in Cereals: A Literature and Patent Review. Int. J. Mol. Sci. 20 (24), 6119. doi: 10.3390/ijms20246119

Compant, S., Brader, G., Muzammil, S., Sessitsch, A., Lebrihi, A., and Mathieu, F. (2013). Use of beneficial bacteria and their secondary metabolites to control grapevine pathogen diseases. BioControl 58 (4), 435-455. doi: 10.1007/s10526012-9479-6

Constantin, M. E., de Lamo, F. J., Vlieger, B. V., Rep, M., and Takken, F. L. W. (2019). Endophyte-mediated resistance in tomato to Fusarium oxysporum is independent of ET, JA, and SA. Front. Plant Sci. 10, 979. doi: 10.3389/ fpls.2019.00979

Cottyn, B., Regalado, E., Lanoot, B., De Cleene, M., Mew, T. W., and Swings, J. (2001). Bacterial populations associated with rice seed in the tropical environment. Phytopathology 91 (3), 282-292. doi: 10.1094/PHYTO.2001.91.3.282

Coutinho, B. G., Licastro, D., Mendonça-Previato, L., Cámara, M., and Venturi, V. (2015). Plant-influenced gene expression in the rice endophyte Burkholderia kururiensis M130. Mol. Plant-Microbe Interact. 28 (1), 10-21. doi: 10.1094/ MPMI-07-14-0225-R

Dini-Andreote, F. (2020). Endophytes: The Second Layer of Plant Defense. Trends Plant Sci. 25 (4), 319-322. doi: 10.1016/j.tplants.2020.01.007

Dissanayake, A. J., Purahong, W., Wubet, T., Hyde, K. D., Zhang, W., Xu, H., et al. (2018). Direct comparison of culture-dependent and culture-independent molecular approaches reveal the diversity of fungal endophytic communities by the Faculty of Agriculture and Ministry of Education, Science and Technological Development, Republic of Serbia, contract no. 451-03-68/2020-14/200116.

\section{ACKNOWLEDGMENTS}

We would like to thank all authors and reviewers who have contributed to our Research Topic. We are sincerely grateful to Prof. Einat Zchori Fein for her initial involvement in the launch of this initiative. We acknowledge Prof. Brigitte Mauch-Mani for contributing as associate editor to the peer-review process.

in stems of grapevine (Vitis vinifera). Fungal Diversity 90 (1), 85-107. doi: 10.1007/s13225-018-0399-3

Garbeva, P., and Weisskopf, L. (2020). Airborne medicine: bacterial volatiles and their influence on plant health. New Phytol. 226 (1), 32-43. doi: 10.1111/ nph. 16282

Gill, S. S., Gill, R., Trivedi, D. K., Anjum, N. A., Sharma, K. K., Ansari, M. W., et al. (2016). Piriformospora indica: potential and significance in plant stress tolerance. Front. Microbiol. 7, 332. doi: 10.3389/fmicb.2016.00332

Gunatilaka, A. A. L. (2006). Natural products from plant-associated microorganisms: distribution, structural diversity, bioactivity, and implications of their occurrence. J. Natural Prod. 69 (3), 509-526. doi: 10.1021/np058128n

Huang, P.-Y., Catinot, J., and Zimmerli, L. (2016). Ethylene response factors in Arabidopsis immunity. J. Exp. Bot. 67 (5), 1231-1241. doi: 10.1093/jxb/erv518

Jung, B., Park, S.-Y., Lee, Y.-W., and Lee, J. (2013). Biological efficacy of Streptomyces sp. strain BN1 against the cereal head blight pathogen Fusarium graminearum. Plant Pathol. J. 29 (1), 52. doi: 10.5423/PPJ.OA.07.2012.0113

Keswani, C., Prakash, O., Bharti, N., Vílchez, J. I., Sansinenea, E., Lally, R. D., et al. (2019). Re-addressing the biosafety issues of plant growth promoting rhizobacteria. Sci. Total Environ. 690, 841-852. doi: 10.1016/j.scitotenv.2019.07.046

Köberl, M., Schmidt, R., Ramadan, E. M., Bauer, R., and Berg, G. (2013). The microbiome of medicinal plants: diversity and importance for plant growth, quality and health. Front. Microbiol. 4, 400. doi: 10.3389/fmicb.2013.00400

Lebeis, S. L., Rott, M., Dangl, J. L., and Schulze-Lefert, P. (2012). Culturing a plant microbiome community at the cross-Rhodes. New Phytol. 196 (2), 341-344. doi: 10.1111/j.1469-8137.2012.04336.x

Ma, Y. (2017). "Beneficial Bacteria for Disease Suppression and Plant Growth Promotion," in Plant-Microbe Interactions in Agro-Ecological Perspectives (Singapore: Springer), 513-529.

Mannaa, M., Park, I., and Seo, Y.-S. (2019). Genomic features and insights into the taxonomy, virulence, and benevolence of plant-associated Burkholderia species. Int. J. Mol. Sci. 20 (1), 121. doi: 10.3390/ijms20010121

Mendes, R., Kruijt, M., De Bruijn, I., Dekkers, E., van der Voort, M., Schneider, J. H. M., et al. (2011). Deciphering the rhizosphere microbiome for disease-suppressive bacteria. Science 332 (6033), 1097-1100. doi: 10.1126/science.1203980

Omomowo, O. I., and Babalola, O. O. (2019). Bacterial and fungal endophytes: Tiny giants with immense beneficial potential for plant growth and sustainable agricultural productivity. Microorganisms 7 (11), 481. doi: 10.3390/ microorganisms7110481

Palazzini, J. M., Ramirez, M. L., Torres, A. M., and Chulze, S. N. (2007). Potential biocontrol agents for Fusarium head blight and deoxynivalenol production in wheat. Crop Prot. 26 (11), 1702-1710. doi: 10.1016/j.cropro.2007.03.004

Pangesti, N., Reichelt, M., van de Mortel, J. E., Kapsomenou, E., Gershenzon, J., van Loon, J. J. A., et al. (2016). Jasmonic acid and ethylene signaling pathways regulate glucosinolate levels in plants during rhizobacteria-induced systemic resistance against a leaf-chewing herbivore. J. Chem. Ecol. 42 (12), 1212-1225. doi: 10.1007/s10886-016-0787-7

Park, K. S., and Kloepper, J. W. (2000). Activation of PR-1a promoter by rhizobacteria that induce systemic resistance in tobacco against Pseudomonas syringae pv. tabaci. Biol. Control 18 (1), 2-9. doi: 10.1006/bcon.2000.0815

Pieterse, C. M. J., Zamioudis, C., Berendsen, R. L., Weller, D. M., Van Wees, S. C. M., and Bakker, P. A. H. M. (2014). Induced systemic resistance by beneficial 
microbes. Annu. Rev. Phytopathol. 52, 347-375. doi: 10.1146/annurev-phyto082712-102340

Salvioli, A., Ghignone, S., Novero, M., Navazio, L., Venice, F., Bagnaresi, P., et al. (2016). Symbiosis with an endobacterium increases the fitness of a mycorrhizal fungus, raising its bioenergetic potential. ISME J. 10 (1), 130-144. doi: 10.1038/ ismej.2015.91

Samain, E., van Tuinen, D., Jeandet, P., Aussenac, T., and Selim, S. (2017). Biological control of septoria leaf blotch and growth promotion in wheat by Paenibacillus sp. strain B2 and Curtobacterium plantarum strain EDS. Biol. Control 114, 87-96. doi: 10.1016/j.biocontrol.2017.07.012

Schlaeppi, K., and Bulgarelli, D. (2015). The plant microbiome at work. Mol. Plant-Microbe Interact. 28 (3), 212-217. doi: 10.1094/MPMI-10-14-0334-FI

Singh, J. S. (2019). New and future developments in microbial biotechnology and bioengineering: microbes in soil, crop and environmental sustainability (Amsterdam, Netherlands: Elsevier).

Trotel-Aziz, P., Couderchet, M., Biagianti, S., and Aziz, A. (2008). Characterization of new bacterial biocontrol agents Acinetobacter, Bacillus, Pantoea and Pseudomonas spp. mediating grapevine resistance against Botrytis cinerea. Environ. Exp. Bot. 64 (1), 21-32. doi: 10.1016/j.envexpbot.2007.12.009

van Dam, P., de Sain, M., Ter Horst, A., van der Gragt, M., and Rep, M. (2018). Use of comparative genomics-based markers for discrimination of host specificity in Fusarium oxysporum. Appl. Environ. Microbiol. 84 (1), e0186817. doi: 10.1128/AEM.01868-17
Van Loon, L. C., Bakker, P., and Pieterse, C. M. J. (1998). Systemic resistance induced by rhizosphere bacteria. Annu. Rev. Phytopathol. 36 (1), 453-483. doi: 10.1146/annurev.phyto.36.1.453

Varma, A., Verma, S., Sahay, N., Bütehorn, B., and Franken, P. (1999) Piriformospora indica, a cultivable plant-growth-promoting root endophyte. Appl. Environ. Microbiol. 65 (6), 2741-2744. doi: 10.1128/AEM.65.6.27412744.1999

Zuccaro, A., Lahrmann, U., Güldener, U., Langen, G., Pfiffi, S., Biedenkopf, D., et al. (2011). Endophytic life strategies decoded by genome and transcriptome analyses of the mutualistic root symbiont Piriformospora indica. PLoS Pathog. 7 (10), e1002290. doi: 10.1371/journal.ppat.1002290

Conflict of Interest: The authors declare that the research was conducted in the absence of any commercial or financial relationships that could be construed as a potential conflict of interest.

Copyright $\odot 2020$ Morelli, Bahar, Papadopoulou, Hopkins and Obradovic. This is an open-access article distributed under the terms of the Creative Commons Attribution License (CC BY). The use, distribution or reproduction in other forums is permitted, provided the original author(s) and the copyright owner(s) are credited and that the original publication in this journal is cited, in accordance with accepted academic practice. No use, distribution or reproduction is permitted which does not comply with these terms. 